\title{
Mental health nursing: issues and roles
}

\section{Kevin Gournay}

1994 saw the publication of the report of the Mental Health Nursing Review Team (Department of Health, 1994). This report signified the end of a three year process where mental health nursing was examined from the perspectives of practice, education, research and management. The last review of mental health nursing took place in 1968 , but since that time there have been enormous changes in our thinking about mental illness, in the delivery of services and a number of very exciting developments in treatment. The review process included the widest possible consultation with other professionals, user organisations, patients, relatives and carers. It also co-opted expert advisers and took written and oral evidence, and visited clinical services across England. There were altogether 42 recommendations and during this article reference will be made to a number of the most important of these.

Before a detailed examination of the issues, it is worth commencing with the tenth recommendation of the review, i.e. that the title Mental Health Nurse (MHN) be used both for nurses who work in the community and for those who work in hospital and day services. Although there are those who would prefer to use the more descriptive term, psychiatric nurse, using one term to cover all nurses is now much more appropriate. MHNs should be using the same core skills regardless of the setting in which they practice. Current thinking about continuity of care reinforces the view that the continued separation of care and treatment between community and in-patient settings is counterproductive.

\section{Serious mental illness}

One of the most important recommendations of the Review was that nurses focus their efforts on those with serious and enduring mental illnesses. This recommendation is in accord with more general public policy and is supported by specific findings. For example, White (1990) in his quinquennial review of Community Psychiatric Nursing in the UK, highlighted the scandalous situation where $80 \%$ of people with schizophrenia in the community had no services whatsoever from a MHN. Only $27.2 \%$ of clients of CPN case loads had a principal diagnosis of schizophrenia and a quarter of CPNs in the UK had no people with schizophrenia on their case loads. At the same time, this survey showed that nurses were increasingly working with populations with depression, anxiety and nonpsychotic problems in primary health care, taking their referrals directly from a GP. Recently Gournay \& Brooking $(1994,1995)$ showed, in a large randomised controlled trial, that $\mathrm{CPN}$ interventions with these populations were both ineffective and very expensive.

Thus, at present the emphasis for MHNs must be with those people with the most serious illnesses, although as will be discussed below, there are limited opportunities for nursing to develop with other populations. Unfortunately, the recent National Survey of Community Mental Health Teams (Onyett et al, 1995) and the Clinical Standards Advisory Group report (DoH, 1995) showed that CPNs still have a long way to go in meeting the recommendations of the Mental Health Nursing Review and that caseloads still comprise many with less serious mental illnesses.

\section{Contemporary services and nursing roles}

Following 40 years of deinstitutionalisation we are now in an era where the unit of delivery of mental

Kevin Gournay is a registered nurse, chartered psychologist, trained nurse behaviour therapist and a new Affiliate of the Royal College of Psychiatrists. He has served on various national initiatives, visited services in the USA and Australia, and is the author of 150 articles, chapters and books. He is Vice Chair of the Mental Health Society at the Royal College of Nursing and Professor of Psychiatric Nursing at the Institute of Psychiatry. 
health care is increasingly the community mental health team. In turn, the mode of delivery is of case management. This was developed from the work of Test \& Stein (1980). The case manager provides a range of interventions, including the brokering of services, establishing networks with community agencies, acting as a client advocate, supervising medication, training the patient in community living skills and using various psychotheraputic and family interventions. Case management should also include the important principle of actively seeking out people who drop out of services. The problem orientated model of case management has been gradually developed in the UK, Australia and the USA (e.g. Hoult, 1991; Marks et al, 1994) and will become much more central to the role of nurses working within community teams.

However, there are two issues which need to be considered further. First, it has become clear that nurses are not the only professionals who will adopt the role of case manager and it may be that in the future this role will also be occupied by occupational therapists, social workers or indeed non-professionals. This was confirmed by Ford et al (1993) in the study of the original case management development sites in the UK. The second issue is that there is often confusion regarding the approach described above, which is predominantly a clinical method, and care management, a term describing what is essentially an over-arching system. To complicate matters further, clinical case management has been developed in different ways with different theoretical underpinnings. For example, the 'strengths' model of case management (Rapp \& Winterstein, 1989) concentrates on building on client strengths rather than targeting deficits. Conversely there are models of case management based on the opposite approach of targeting deficits; for example using social skills training as a central intervention. Detailed discussion of the various models of case management is out of place here but recent research has begun to identify which approaches are more effective. For a detailed discussion the reader is referred to Andrews \& Teesson (1994), Muijen (1994) and Santos et al (1995).

In summary, the research findings so far indicate that clinically focused approaches are the most effective and that the brokerage models favoured by many Social Services departments may actually lead to negative outcomes (Curtis et al, 1992; Rossler et al, 1992). Although case management has become more widespread it is in itself not a panacea and certainly demands that staff are appropriately trained. For example, Muijen (1994) showed that merely reconfiguring nursing teams within case management arrangements conferred no additional benefit over nurses working in their usual generic fashion.

\section{Dual diagnosis populations}

Nurses in contemporary services are increasingly working with new populations which will demand changes in approach. For example, the dual diagnosis of substance misuse and serious mental illness is now a growing and substantial problem. A range of work from the US (Bartels et al, 1995; Teague et al, 1995) shows that an integrated approach to both serious mental illness and substance misuse and/or dependence is necessary for a positive outcome.

Although the majority of people with serious mental illness are no more dangerous than the general population, violence is an increasing problem in services. Work from the US (e.g. Torrey, 1994) shows that violence is particularly linked to patients who abuse substances and those who are non-compliant with medication. Although some research (Dvoskin \& Steadman, 1994) has shown that intensive case management can reduce it, violence places increasing stress on mental health team workers and makes conditions of work that much harder.

\section{Neglected nursing roles}

\section{Physical health}

There are two areas traditionally associated with nursing which have been gradually neglected over the years. The physical health of people with longterm mental illnesses is, of course, an important area for attention, particularly as we know that standardised mortality rates in schizophrenia are 2.5 times those of the rest of the population and $45 \%$ of people with long-term mental illness also have substantial physical illnesses, particularly those of the cardiovascular and respiratory variety (Allbeck, 1989; DoH, 1995). Furthermore, we also know that this population is at considerable risk from infection with HIV (Sacks et al, 1990). Obviously medical care is the responsibility of both the patient's GP and the responsible Medical Officer of the mental health team. However, as recent work (DoH, 1995) shows, patients do not always receive appropriate physical monitoring. This may be for many reasons, for example, not registering with a GP, or the GP assuming that the 
Box 1. Important roles in serious mental illness

Case management

Psychosocial interventions

Physical health - monitoring and education

Medication management

Working with dual diagnosis patients

Behavioural therapy

Mental Health Service is attending to these needs. MHNs are ideally placed to ensure that patients are properly registered with a GP and that any clearly defined problems receive appropriate attention. Further, nurses can monitor weight, blood pressure and also provide health education and interventions in areas such as diet, smoking and sexual behaviour.

\section{Medication management}

MHNs have a natural central role in ensuring that medication is managed effectively. The importance of this cannot be overstated, particularly as there is a wide array of evidence (McCreadie et al, 1992) which shows that the majority of people with schizophrenia being treated with psychotropic medication have significant side-effects. Unfortunately medication management has not been high on the list of priorities for practice or education (White, 1990), and recent research (e.g. Bennett $e t$ $a l, 1995 a, b)$ shows that nurses are often not sufficiently skilled to detect even the most serious side-effects of neuroleptic medication. There have been some commendable initiatives recently such as the guidance document issued jointly by the Department of Health and the Royal College of Nursing (1995). However, educators and managers in mental health nursing do need to place more emphasis on this important area, particularly as a new generation of drugs are gradually coming on to the market, each of these compounds having their own profile of actions and side-effects.

\section{Nurse behaviour therapists}

While there is a clear case for focusing on serious mental illness, we have known for many years that severe phobic and obsessional states can cause tremendous handicaps. However, the majority of sufferers can be helped dramatically by brief behavioural psychotherapy (Marks, 1987). The recognition that adequate numbers of sufferers could not be treated by psychiatrists or clinical psychologists alone, led to the setting up of the first Nurse Therapy Training Programme at the Maudsley Hospital in 1972 (Marks et al, 1977). Several studies have shown that nurse therapists produce excellent results in terms of both clinical and economic outcomes (Ginsberg et al, 1984).

However, despite strong evidence, only about 200 nurse therapists have been trained since 1972 and therefore their impact on the health care system has been very limited. There is no reason why we should not develop new nurse therapy training programmes. Experienced nurse therapists could also provide support and supervision for more numerous groups, such as practice nurses and nonprofessionals, to deliver simple exposure-based programmes. These skills could probably be taught in a relatively short space of time to these personnel.

\section{Education and training}

\section{Psychosocial interventions - the Thorn Programme}

The UK is currently leading the world in the development of comprehensive training initiatives. The Sainsbury Centre in London has developed case management in various demonstration sites throughout the UK and their training division assists many local services. Furthermore, Masters programmes in problem orientated case management and psychosocial interventions are gradually developing in universities. For example, the author developed a multi-disciplinary programme in 1992, and Brooker commenced a similar programme in Sheffield in 1995. However, the most important development is the Thorn Nurse Initiative. This is based at the Institute of Psychiatry in London and at Manchester University, and was set up by a generous grant from the Sir Jules Thorn Trust. The first programme was developed by a team of influential psychiatrists, nurses and psychologists, including Dr Jim Birley, Professors Isaac Marks, Tom Craig, Julian Leff, Nick Tarrier, Tony Butterworth, and other colleagues. The year-long course sets out to produce a specialist nurse dedicated to work with patients with schizophrenia, analogous to the Macmillan nurse for cancer. Training is skills-based and focuses on a clinically focused and problem orientated method 
of case management. There is also training in the various contemporary psychosocial methods, including family management, cognitive-behavioural interventions with positive and negative symptoms, and prodrome and relapse strategies.

By the end of 1995 this programme had produced about 60 graduates and the plan is for satellite centres to be set up throughout the UK over the next couple of years. The programme has attempted to ensure rigorous adherence to training principles and the use of clinical supervision, as research shows that at follow-up, after training in psychosocial interventions, both of these issues seemed problematic (Kavanagh et al, 1993; McFarlane et al, 1993). Initially it was envisaged that the Thorn programme would be confined to nurses, but by late 1995 the Manchester programme had begun to admit others and the Institute of Psychiatry programme will probably also soon open its doors to psychologists, occupational therapists, and social workers.

There is a need to evaluate the work of Thorn nurses in some detail, particularly as case management outcome is still far from clear (e.g. Andrews \& Teesson, 1994; Muijen, 1994; Santos et al, 1995). The Thorn programme has an integral evaluation of clinical outcomes of patients treated by students. However, full scale studies with randomised controlled trials are still some way off. On a positive note, Brooker et al $(1992,1994)$ have already demonstrated that CPNs can be trained, using relatively brief programmes, to become effective deliverers of family interventions.

\section{Undergraduate nurse education}

The education and training of nurses is now the responsibility of universities, the framework being Project 2000. Essentially this means that nurse training has become much more theory based, with a move away from apprenticeship. All nurses now receive a basic education within a common foundation programme for 18 months and after that they spend another 18 months studying either general nursing, mental health nursing, learning disabilities nursing or child nursing. It is likely that nursing will soon become an all graduate profession and that specialisms such as mental health will only be available at Masters level. This development is much against the recommendations of the Mental Health Nursing Review, which drew attention to the problems associated with genericism in social work and recommended unequivocally that mental health nursing be retained in its present form (Box 2). Should nursing become an allgraduate and generic profession, it seems likely that none of the nurses of the future will want to attend to basic nursing care tasks for the mentally ill, and instead of receiving attention from a skilled registered nurse, patients will receive direct care from health care assistants, with a nurse acting as a supervisor.

There are three other major difficulties associated with nurse education. First, the Mental Health Nursing Review recognised that nurse tutors are very often removed from the realities of clinical practice and recommends that they spend at least a day a week in a clinical area. However, this recommendation does not go far enough, the optimum arrangement is that of a lecturerpractitioner with a $50-50$ split. The second problem is that the current mental health nursing curriculum contains a great deal of arguably redundant theory which is often underpinned by an anti-psychiatric philosophy. On the other hand, there seems to be very little information regarding the biological aspects of mental illness or indeed little skills training in important areas such as medication management.

The final area of education which is of paramount importance concerns the large numbers of nurses who were trained in and have spent all of their working lives working in large institutions. It is completely unreasonable to expect these nurses to make the transition to community mental health teams without training. However, this is happening all over the country. Once more, we are drawn to the issue of investment in training and it is arguable

Box 2. Recommendations of the Mental Health Nursing Review

(6) "The essential focus lies in working with people with serious or enduring mental illness"

(10) "The title Mental Health Nurse be used for nurses who work in the community and for those who work in hospital and day services"

(12) "Action is taken to improve the standards of management and leadership"

(19) "The collective and individual needs of nurses presently working in large mental hospitals should be identified and met"

(32) "Teachers of mental health nursing should spend the equivalent of at least one day per week in practice" 
that this represents, alongside the provision of sufficient residential facilities, the biggest priority for future action.

\section{Management}

The Review was particularly concerned that the standards of management and leadership in mental health nursing needed strengthening and consequently the Department of Health has set up a programme to develop the leadership potential of small numbers of mental health nurses. The Review also recommended that nursing managers develop strategies with particular emphasis on use of Standards Protocols. Thus the recent Clinical Standards Project on schizophrenia provides nurses with a framework for action. Finally, the Review recognised that nurse managers need to adapt to the contemporary demands of multi-disciplinary/ inter-agency working and recommended greater collaboration with other social and health care providers.

\section{Research}

The Review recognised that research in mental health nursing needs strengthening and made several recommendations to assist with the development of an appropriate infrastructure. These include the setting up of information systems and targeting central Research and Development resources on mental health nursing activity. It also seems essential that research in mental health nursing be much better integrated with the efforts of other disciplines. Furthermore, nursing interventions should be subjected to the tests of randomised controlled trials and economic analysis. Unfortunately such methods have rarely been used by nursing researchers who have generally concentrated on qualitative methods. Hopefully the establishment of mental health nursing departments within our medical schools and universities, which is now taking place, will lead to researchers being able to benefit from the collaboration and supervision of more established groups.

\section{Conclusion}

Mental health nursing, like the rest of mental health care, is in a state of rapid transition. There are clearly many opportunities for the development of mental health nursing skills and these can only be beneficial for the sufferers of mental illness. However, there are also many challenges for mental health nursing to confront in the future. Fortunately we can be guided by important work such as the Mental Health Nursing Review and the Clinical Standards Advisory Group on Schizophrenia, and these provide the basis for future action and thus improvement in what mental health nursing has to offer.

\section{References}

Allbeck, P. (1989) Schizophrenia: a life shortening illness. Schizophrenia Bulletin, 15, 81-89.

Andrews, G. \& Teesson, M. (1994) Smart versus dumb treatment: services for mental disorder. Current Opinion in Psychiatry, 7, 181-185.

Bartels, S., Drake, R. \& Wallach, M. (1995) Long-term course of substance use disorders among persons with severe mental illness. Psychiatric Seroices, 46, 248-251.

Bennett, J., Done, J., Harrison-Read, P., et al (1995a) Development of a rating scale - check list to assess the side-effects of antipsychotics by Community Psychiatric Nurses. In Community Psychiatric Nursing: A Research Perspective (vol 3) (ed by C. Brooker \& E. White), pp 1-19. London: Chapman \& Hall.

- - \& Hunt, B. (1995b) Assessing the side-effects of antipsychotic drugs: a survey of CPN Practice. Journal of Psychiatric Mental Health Nursing, 2, 177-182.

Brooker, C., Tarrier, N., Barrowclough, C., et al (1992) Training Community Psychiatric Nurses for psychosocial intervention: report of a pilot study. British Journal of Psychiatry, 160, 836-844.

-, Falloon, I., Butterworth, A., et al (1994) The outcome of training psychiatric nurses to deliver psychosocial intervention. British Journal of Psychiatry, 165, 222-230.

Curtis, J., Millman, E., Struening, E., et al (1992) Effect of case management on rehospitalisation and neutralisation of ambulatory case services. Hospital and Community Psychiatry, 43, 895-899.

Department of Health (1994) The Report of the Reveiw of Mental Health Nursing. London: HMSO.

- (1995) Report of the Schizophrenia Committee of the Clinical Standards Advisory Group. London: HMSO.

- \& Royal College of Nursing (1995) Good Practice in the Administration of Depot Neuroleptic Drugs; A Guidance Document for Mental Health \& Practice Nurses. Manchester: BAPS, Health Publication Unit.

Dvoskin, J. \& Steadman, H. (1994) Using intensive case management to reduce violence by mentally ill persons in the community. Hospital and Community Psychiatry, 45, 679684.

Ford, R., Beadsmoore, A., Norton, P., et al (1993) Developing case management of the long term mentally ill. Psychiatric Bulletin, 17, 409-411.

Ginsberg, G., Marks, I. M. \& Walters, H. (1984) Cost benefits in a controlled trial of nurse therapy for neuroses in primary care. Psychological Medicine, 14, 683-690.

Gournay, K. J. M. \& Brooking, J. I. (1994) The community psychiatric nursing primary care: an outcome study. British Journal of Psychiatry, 165, 231-238.

— \& - (1995) The community psychiatric nursing primary care: an economic analysis. Journal of Advanced Nursing, 22, 169-178.

Hoult, J. (1991) Home treatments in New South Wales. In The Closure of Mental Hospitals (eds P. Hall \& I. F. Brockington), pp. 107-114. London: Gaskell. 
Kavanagh, D., Clark, D., Piat Kowska, O., et al (1993) Application of cognitive behavioural family interventions for schizophrenia: what can the matter be? Australian Psychologist, 28, 1-8.

Marks, I. M. (1987) Fears, Phobias and Rituals. Oxford: Oxford Medical.

-, Connerly, J., Hallam, R., et al (1977) Nursing in Behavioural Psychotherapy. London: RCN Publications.

-, - Muijen, M., et al (1994) Homebased versus hospital based care for people with serious mental illness. British Journal of Psychiatry, 165, 179-194.

McCreadie, R. G., Robertson, L. J. \& Wiles, D. H. (1992) The Nithsdale schizophrenia survey: akathisia, Parkinsonism, tardive dyskinesia and plasma neuroleptic levels. British Journal of Psychiatry, 160, 793-799.

McFarlane, W., Dunne, E., Lukens, E., et al (1993) From research to clinical practice: dissemination of New York State's family psychoeducation project. Hospital and Community Psychiatry, 44, 265-270.

Muijen, M. (1994) Rehabilitation in the care of the mentally ill. Current Opinion in Psychiatry, 7, 202-206.

Newell, R. \& Gournay, K. J. M. (1994) British nurses in behavioural psychotherapy: a 20 year follow-up. Journal of Advanced Nurses, 20, 53-60.

Onyett, S., Pillinger, T. \& Muijen, M. (1995) Making Community Mental Health Teams Work. London: Sainsbury Centre.

Rapp, C. \& Winterstein, R. (1989) The strengths model of case management: results from 12 demonstrations. Psychosocial Rehabilitation Journal, 13, 23-32.

Rossler, W., Loffler, W., Fatkenheuer, B., et al (1992) Does case management reduce the rehospitalisation rate? Acta Psychiatrica Scandinavica, 86, 445-449.

Santos, A., Henggeler, S., Burns, B., et al (1995) Research on field based services: models for reform in the delivery of mental health care to populations with complex clinical problems. American Journal of Psychiatry, 152, 1111-1123.

Sacks, N., Terry, F. \& Braver, R. (1990) Self-reported HIV related risk behaviours in acute psychiatric out-patients. Hospital and Community Psychiatry, 41, 1253-1255.

Teague, G., Drake, R. \& Ackerson, T. (1995) Evaluating use of continuous treatment teams for persons with mental illness and substance abuse. Psychiatric Services, 46, 689-695.

Test, M. A. \& Stein, L. (1980) Alternative to mental hospital treatment. III. Social cost. Archives of General Psychiatry, 37, 409-412.

Torrey, E. (1994) Violent behaviour by individuals with serious mental illness. Hospital and Community Psychiatry, 45, 653662.

White, E. (1990) A Quinquennial Survey of Community Psychiatric Nursing. University of Manchester: Department of Nursing.

\section{Multiple choice questions}

1 Latest research shows that CPNs' case loads include:
a $80 \%$ of people with schizophrenia in the community
b $50 \%$
c $20 \%$

2 The most effective form of case management is: a Clinically focused model

b Brokerage model

c Strengths model

3 Standardised mortality rates in schizophrenia are:

a $1.5 \%$ that of the general population

b $2.5 \%$ that of the general population

c $3.5 \%$ that of the general population

4 The Thorn Nurse initiative is based on:

a Behaviour therapy

b Case management, family management and behaviour therapy

c Anti-psychiatric theories

MCQ answers

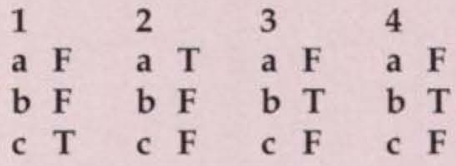

